\title{
Diagnostic accuracy of tumor necrosis factor-alpha, interferon-gamma, interlukine-10 and adenosine deaminase 2 in differential diagnosis between tuberculous pleural effusion and malignant pleural effusion
}

\author{
Mingying Li, Helin Wang, Xia Wang, Jian Huang, Junxiang Wang and Xiue Xi
}

\begin{abstract}
Background: The current study was performed to investigate the potential biomarkers for the differential diagnosis of tuberculous pleural effusion (TPE) and malignant pleural effusions (MPE).

Methods: Among ninety patients $(n=90)$ involved in the study, 47 with tuberculous pleural effusion aged from 18 to 70 and 43 with secondary malignant pleural effusion aged from 34 to 78 . We tested the pleural levels of TNF-a, IFN- $\gamma$ and IL-10 as well as the enzyme activity of $\mathrm{ADA}_{2}$, and then we compared the differential diagnostic efficiencies of those biochemical parameters with ADA between the two groups.

Results: Our results show that, the concentrations of pleural TNF-a (45.55 $\pm 15.85 \mathrm{ng} / \mathrm{L})$, IFN- $\gamma(114.97 \pm 27.85 \mathrm{ng} / \mathrm{L})$ as well as activities of $\mathrm{ADA}_{2}(35.71 \pm 10.00 \mathrm{U} / \mathrm{L})$ and $\mathrm{ADA}(39.39 \pm 10.60 \mathrm{U} / \mathrm{L})$ in tuberculous group were significantly higher compared to malignant group. Furthermore, according to the ROC curve analysis the thresholds of TNF-a, IFN- $\gamma, A_{1} A_{2}$ and ADA were found to be $30.3 \mathrm{ng} / \mathrm{L}, 103.65 \mathrm{ng} / \mathrm{L}, 29.45 \mathrm{U} / \mathrm{L}$, and $39.00 \mathrm{U} / \mathrm{L}$, respectively. TNF-a, IFN- $\gamma$ and $\mathrm{ADA}_{2}$ yielded better sensitivity, specificity, and accuracy of the diagnosis than ADA. Our investigation further revealed that the combinations of TNF- $a$ and $\mathrm{ADA}_{2}$ further increased the specificity and accuracy for the differential diagnosis.
\end{abstract}

Conclusion: In conclusion, we found that TNF-a, IFN- $\gamma$, ADA and ADA $_{2}$ all increased in TPE. Combinations of the TNF- $a$ and $\mathrm{ADA}_{2}$ yielded the best specificity and accuracy for the differential diagnosis of TPE from MPE. Our investigation suggests that the applications of TNF-a together with $\mathrm{ADA}_{2}$ may contribute to more efficient diagnosis strategies in the management of discrimination between tuberculous and malignant pleural effusions.

Keywords: Tuberculous pleural effusion, Malignant pleural effusion, Differential diagnostic significance, Tumor necrosis factor-alpha, Interferon-gamma, Interlukine-10, Adenosine deaminase 2

\footnotetext{
* Correspondence: Xiuexi01@yahoo.com

The First Affiliated Hospital of Xinxiang Medical University, No.88 Jiankang Road, Weihui 453100, Henan Province, China
} 


\section{Background}

Most of pulmonary and systemic diseases may be associated with pleural effusion. It is a common clinical problem and it has been estimated that there are $>800,000$ cases/ year in the USA [1]. Tuberculosis and malignant diseases involving the pleura are the leading causes of pleural effusion, which has an occurrence of $49.6 \%$ and $29.6 \%$, respectively, especially in the under developed areas among all pleural effusion cases, respectively [2-5]. Thus, it is of great clinical significance to explore efficient biochemical markers for making differential diagnosing of tuberculous pleural effusion (TPE) from malignant pleural effusion (MPE). The diagnosis of TPE is made by detecting Mycobacterium tuberculosis in the pleural fluids and/or pleural biopsy specimens, or demonstrating caseation granulomas in pleura [6]. However, only $10-35 \%$ of biological culture and $20-81 \%$ of molecular tests reveal mycobacteria in pleural fluids, and pleural biopsy demonstrates granulomas in $56-82 \%$ of samples [7-10]. In addition, the financial problem is a burden for the patients as well. Furthermore, the discrimination from MPE, which is mainly diagnosed based on the pathological methods, is still a challenge.

It is reported that adenosine deaminase (ADA), tumor necrosis factor-alpha (TNF- $\alpha$ ), interferon-gamma (IFN- $\gamma$ ), interlukine-12 (IL-12), interlukine-18 (IL-18), interlukine10 (IL-10), interlukine-27 (IL-27), Immunosuppressive acidic protein (IAP), and soluble IL-2 receptor could serve as differential diagnosis biomarkers for pleural effusion caused by TB or malignant diseases $[7,11,12]$. Adenosine deaminase (ADA), a purine-degrading enzyme implicated in mononuclear phagocyte maturation, has been reported to accumulate in the pleural fluid of TB patients and being predict TB pleurisy with high sensitivity and specificity at $95 \%$ and $90 \%$ respectively [6]. The accumulation of ADA in pleural fluid results mainly from one of its isoforms, $\mathrm{ADA}_{2}$, with which a diagnosis of tuberculous pleurisy could be verified [13]. In the past decade, researchers demonstrated that both tuberculous and malignant pleural effusions show marked increase of TNF- $\alpha$ [14-17]. And the up-regulated IFN- $\gamma$ and IL10 in fluid can be diagnostic parameters for tuberculous pleural effusion as well. Most recently, interlukine (IL)27, a member of IL-12 family, has been verified useful in diagnosing TPE or discriminating pleural effusions caused by tuberculosis from other medical situations $[12,18]$. However, none of those is widely used in clinical practice currently but it is only restricted to research settings.

In this present study, we aimed at exploring the potential series of diagnostic biomarkers. In order to figure out the clinical significance of these diagnostic parameters for the discriminating diagnosis of tuberculous and malignant pleural effusions, concentrations of TNF- $\alpha$,
IFN- $\gamma$ and IL-10 and enzyme activity of $\mathrm{ADA}_{2}$ were measured and compared with ADA activity.

\section{Methods}

\section{Patients and sample collection}

A total of 90 patients $(n=90)$ admitted in Henan Tuberculosis Hospital between Jun. 2010 and May. 2012 were involved in this research (Table 1). All patients have been diagnosed based on clinical symptoms, pleural effusion analysis, and/or pleural biopsy specimen observation. Accordingly, the subjects were determined as tuberculous pleural effusion based on the presence of either positive staining or culture for M. tuberculosis in the pleural fluid, sputum or pleural biopsy specimen or caseating granulomas on pleural biopsy. Secondary malignant pleural effusion diagnosis was based on the determination of malignant cells on cytological examination or in a biopsy specimen, or by histologically determined primary malignance with the exclusion of any other cause of pleural effusion. Among all the 43 patients, there were 26 patients with lung cancer (60.5\%), 6 patients with breast cancer (14.0\%), 7 metastatic cancer patients with unknown idiopathy (16.3\%), and 4 patients with stomach, pancreatic or ovary cancer (9.3\%). All pleural fluid samples were collected by thoracentesis prospectively before the patients undergone any medical treatments. Collected samples from all the patients were centrifuged and kept in freezer in $-70^{\circ} \mathrm{C}$.

This study was approved by the Ethics Committee of Henan Tuberculosis Hospital. Study participants and/or their legal guardians granted written-informed consent.

\section{Determination of cytokines' concentration and enzyme activities of ADA and $\mathrm{ADA}_{2}$}

Enzyme-linked immunosorbant assay (ELISA) was performed according to manufacturer's instructions to determine the pleural concentrations of TNF- $\alpha$, IFN- $\gamma$ and IL-10 using commercial kits (Biosource). Pleural enzyme activity of ADA and $\mathrm{ADA}_{2}$ were determined by spectrophotometric method according to Muraoka's [19] method. In detail, the catalyzed enzyme activity of $\mathrm{ADA}$ or $\mathrm{ADA}_{2}$ was determined by quantifying hypoxanthine liberated from the substrate $(1 \mathrm{U} / \mathrm{L})$ under the atmosphere of $37^{\circ} \mathrm{C}$ and pH7.1. The substrate of ADA was composed of adenosine $(6 \mathrm{mM}), \gamma$ - oxoglutarate $(1.1 \mathrm{mM})$, ADP $(1 \mathrm{mM})$ and glutamate dehydrogenase $(18 \mathrm{U} / \mathrm{L})$. And the $\mathrm{ADA}_{2}$

Table 1 Clinical information of patients

\begin{tabular}{ccccc}
\hline & & \multicolumn{2}{c}{ Gender } & \\
\cline { 3 - 4 } Group & Case & $\mathbf{M}$ & $\mathbf{F}$ & Age \\
\hline Tuberculous & 47 & 29 & 18 & $51.3 \pm 11.8$ \\
Malignant & 43 & 23 & 20 & $55.5 \pm 12.4$ \\
\hline
\end{tabular}

Comparison between gender $X^{2}=0.263, P>0.05$.

Comparison between age $t=1.646, P>0.05$. 
activity was determined by the same substrate with the presence of erythro-9-(2-hydroxy-3- nonyl) adenine hydrochloride (EHNA, $0.1 \mathrm{mM}$ ). The enzyme activities absorbance was read at $340 \mathrm{~nm}$ using automatic biochemical analyzer (Olympus AU600). Here, the enzyme activity ( $1 \mathrm{U} / \mathrm{L}$ ) was defined as $1 \mu \mathrm{M}$ hypoxanthine liberating from catalyzed adenosine per minute. All samples were assayed in duplicate.

\section{Statistical analysis}

Computerized statistical analyses were performed using the Statistical Package for the Social Sciences (SPSS), version 17.0. The variances of different biomarkers among different groups were analyzed using Mann-Whitney $U$-test, the comparison of sensitivity and specificity was analyzed by $\chi^{2}$ test. Sensitivity and specificity values providing the best test performance and the area under the curve (AUC) were calculated using a receiver operating characteristic (ROC) curve analysis. In all statistical analyses, a two-tailed $p$ value $\leq 0.05$ was considered statistically significant. Data were presented as mean \pm standard error (SE).

\section{Results}

\section{Clinical information of patients}

In our study neither age nor gender has any statistical significance between groups (Table 1).

\section{Concentration of pleural cytokines and enzyme activities of ADA and $\mathrm{ADA}_{2}$}

We assayed the concentrations of pleural TNF- $\alpha$, IFN- $\gamma$, IL-10 as well as the activities of ADA and its isoenzyme, $\mathrm{ADA}_{2}$. Then we compared the diagnostic efficiencies of the cytokines and $\mathrm{ADA}_{2}$ with $\mathrm{ADA}$, which is well known for the high diagnostic value for tuberculous pleural effusion. The level of TNF- $\alpha$ was up-regulated significantly in tuberculous group from $17.18 \pm 4.84 \mathrm{ng} / \mathrm{L}$ to $45.55 \pm$ $15.85 \mathrm{ng} / \mathrm{L}$ compared to malignant group. In addition, the pleural IFN- $\gamma$ was higher in tuberculous group $(114.97 \pm 27.85 \mathrm{ng} / \mathrm{L})$ than in malignant group $(87.15 \pm$ $18.77 \mathrm{ng} / \mathrm{L})$ as well $(\mathrm{p}<0.001)$. The enzyme activities of ADA in tuberculous and malignant pleural fluid were $39.39 \pm 10.60 \mathrm{U} / \mathrm{L}$ and $32.16 \pm 6.99 \mathrm{U} / \mathrm{L}$ respectively. The $\mathrm{ADA}_{2}$ activity was $35.71 \pm 10.00 \mathrm{U} / \mathrm{L}$ and
$20.87 \pm 4.53 \mathrm{U} / \mathrm{L}$ in tuberculous and malignant pleural effusion respectively as shown in Table 2. However, there was no statistical significance on the level of pleural IL-10 between these two groups.

\section{Differential diagnostic values of TNF- $a$, IFN-,- ADA and $\mathrm{ADA}_{2}$}

ROC curve analysis was introduced to evaluate the cut-off values of pleural TNF- $\alpha$, IFN- $\gamma, \mathrm{ADA}$ and $\mathrm{ADA}_{2}$ (Figure 1). The thresholds were found to be $30.3 \mathrm{ng} / \mathrm{L}, 103.65 \mathrm{ng} / \mathrm{L}$, $39.00 \mathrm{U} / \mathrm{L}$ and $29.45 \mathrm{U} / \mathrm{L}$ respectively (Table 3 ). Unfortunately, when compared to ADA, no statistical significance was found on the area under the curve (AUC) value of TNF- $\alpha$, IFN- $\gamma$ and $\mathrm{ADA}_{2}(\mathrm{p}>0.05)$ (Table 3$)$. But the AUC for all of these bio parameters are greater than 0.5 , TNF- $\alpha$ (0.976), IFN- $\gamma$ (0.831) and $\mathrm{ADA}_{2}$ (0.844), indicating that TNF- $\alpha$, IFN- $\gamma$ and $\mathrm{ADA}_{2}$ are reliable for the clinical diagnosis of TPE.

With a cut-off value of $30.3 \mathrm{ng} / \mathrm{L}$, the sensitivity of TNF- $\alpha$ for differential diagnosis of TPE from MPE was $83 \%$, with the specificity of $97 \%$ and accuracy of $90 \%$ (Table 3). Also as shown in Table 3, with a cut-off value of $103.65 \mathrm{ng} / \mathrm{L}$, the sensitivity of IFN- $\gamma$ was $80.9 \%$, specificity was $81.4 \%$ and accuracy was $81.1 \%$. Furthermore, our data indicated that $\mathrm{ADA}_{2}$ yielded slightly better specificity of $97 \%$ and accuracy of $86.7 \%$ than ADA but equivalent sensitivity of $76.6 \%$ for the differential diagnosis of the diseases (Table 3).

\section{Combined-diagnostic value of TNF- $\alpha$, IFN- $\gamma$ and ADA $_{2}$}

The question of the possibility of the combinations of two or three of the parameters would improve the diagnostic sufficiency for differentiating tuberculous pleural effusion from malignancy is raised. As a result, we further investigated the potential combined-diagnostic value of TNF- $\alpha$, IFN- $\gamma$ and $\mathrm{ADA}_{2}$. Parallel tests were introduced in our analysis to evaluate the differential diagnostic significances of the biochemical parameters of interests for tuberculous or malignant pleural effusion. When two or three parameters of TNF- $\alpha$, IFN- $\gamma$ and $\mathrm{ADA}_{2}$ were used for diagnosis, the measurement of TNF- $\alpha$ plus $\mathrm{ADA}_{2}$ yielded the highest specificity (97.7\%) and accuracy (88.3\%) but slight increase in sensitivity (78.9\%) (Table 4) for discriminating tuberculous pleural effusion from malignant pleural effusion.

Table 2 Pleural fluid enzyme activities of ADA and ADA ${ }_{2}$, concentrations of TNF- $a$, IFN- $\gamma$ and IL-10 ( $\pm s$ )

\begin{tabular}{llllllll}
\hline Group & $\mathbf{n}$ & $\begin{array}{l}\mathbf{A D A} \\
(\mathbf{U} / \mathbf{L})\end{array}$ & $\begin{array}{l}\mathbf{A D A}_{\mathbf{2}} \\
\mathbf{( U / L )}\end{array}$ & $\begin{array}{l}\mathbf{A D A}_{\mathbf{2}} / \mathbf{A D A} \\
\mathbf{( \% )}\end{array}$ & $\begin{array}{l}\text { TNF-a } \\
\text { (ng/L) }\end{array}$ & $\begin{array}{l}\text { IFN- } \boldsymbol{\gamma} \\
\text { (ng/L) }\end{array}$ & $\begin{array}{l}\text { IL-10 } \\
\text { (ng/L) }\end{array}$ \\
\hline Tuberculous & 47 & $39.39 \pm 10.60$ & $35.71 \pm 10.00$ & 90.63 & $45.55 \pm 15.85$ & $114.97 \pm 27.85$ & $6.12 \pm 2.31$ \\
Malignant & 43 & $32.16 \pm 6.99$ & $20.87 \pm 4.53$ & 64.89 & $17.18 \pm 4.84$ & $87.15 \pm 18.77$ & $6.20 \pm 2.29$ \\
$t$ & & 5.74 & 12.76 & 56.89 & 12.26 & 5.28 & 0.994 \\
$P$ & & $<0.001$ & $<0.001$ & $<0.001$ & $<0.001$ & $<0.001$ & $>0.05$ \\
\hline
\end{tabular}

$\mathrm{n}=$ number of subject; Values are mean $\pm \mathrm{SD}$. 


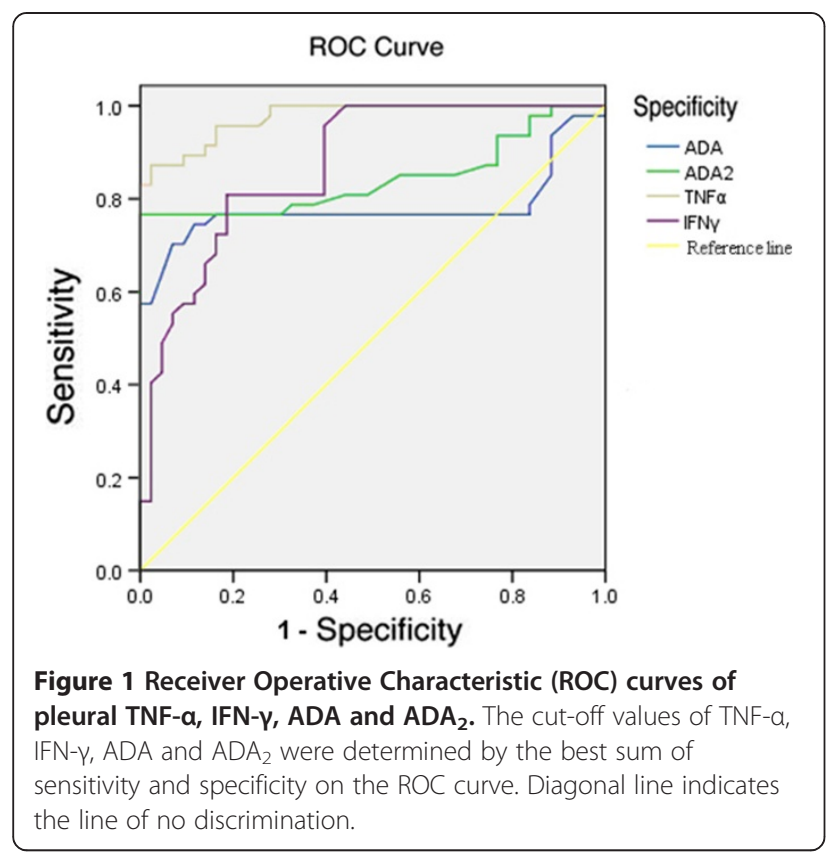

\section{Discussion}

Tuberculosis and secondary malignant diseases are the leading causes of pleural effusion. Although the pleural fluids were mainly composed of lymphocytes both in TPE and MPE, clinical treatments and prognosis vary significantly. Thus, differential determination plays a key role in the clinical procedure of pleural effusion. Tuberculous pleurisy is diagnosed based on the positive culture of pleural M. tuberculosis or demonstrating the characteristic caseation granulomas in pleural biopsy specimens [6]. However, histological or bacteriological confirmation for tuberculous pleurisy is of lower sensitivity or accuracy. The lack of more efficient diagnostic criteria drove investigators to explore a specific marker for diagnosis of diseases.

In the past decades, series of bio-parameters were reported to play a role in the differential diagnosis of tuberculous and malignant pleural effusions. Among which, ADA, a purine-degrading enzyme that catalyze the conversion of adenosine and deoxyadenosine to inosine and deoxyinosine with the release of ammonia, is the most sensitive and specific marker for tuberculosis pleurisy diagnosis [20-23]. Meanwhile, $\mathrm{ADA}_{2}$, isoform of ADA, was reported to be a useful biochemical marker for the early diagnosis of tuberculous pleural effusion and differentiate tuberculous pleural effusion from nontuberculous origins efficiently [24]. As shown in this study, the sensitivity and specificity yielded for ADA on the diagnosis of tuberculosis pleurisy are $76.6 \%$ and $83.7 \%$, respectively, which are in agreement with previous studies. Based on these results, we further confirmed the clinical significance of $\mathrm{ADA}_{2}$. Meanwhile, the ratio of $\mathrm{ADA}_{2}$ to the total ADA (mean: 90.63\%) increased significantly in the tuberculosis group, indicating the increased pleural $\mathrm{ADA}_{2}$ accounts for the high activity of ADA in the effusion fluid. As a delayed hypersensitivity reaction, TB was resistant by Th1 type immune response of the body, which enables $\mathrm{ADA}_{2}$ up regulated in the pleural fluid. As shown in our study, pleural $\mathrm{ADA}_{2}$ yielded the great sensitivity of $76.6 \%$ and the highest specificity of $97 \%$ on the diagnosis of tuberculous pleurisy. Unfortunately, no statistical significance was found when compared with ADA. However, it was reported that ADA activity may be lower at the early stage of tuberculous pleurisy and the high activities may decrease long after onset of the disease as well [13]. Recently it was reported that the increased ADA activity was not restricted in tuberculous pleurisy but in the pleural fluid associated with pyothorax, lymphoma or ILS [6]. Therefore we further investigated other diagnostic bio parameters, hoping to discover a reliable biomarker for the diagnosis of tuberculosis associated pleural effusion.

Tumor necrosis factor- $\alpha$ (TNF- $\alpha$ ), a small polypeptide, functions on biological and immunological processes. It is a pro-inflammatory cytokine, which is synthesized by lymphocytes and monocytes/macrophages [25]. As a Th1 subset member, it plays an important role in antiinflammation reaction and tumor resistant process. Previous literatures demonstrated significant accumulated TNF- $\alpha$ in pleural fluid of TB [26] comparing to the malignant pleural effusion. As expected, we detected the upregulated pleural level of TNF- $\alpha(45.55 \pm 15.85 \mathrm{ng} / \mathrm{L})$ in the TB pleural fluid, which is significantly higher than that of malignant $(17.18 \pm 4.84 \mathrm{ng} / \mathrm{L})$ group. Meanwhile, with a cut off of $30.3(\mathrm{ng} / \mathrm{L})$, the sensitivity and specificity of TNF- $\alpha$ for tuberculous pleurisy diagnosis were determined to be the highest, $83 \%$ and $97 \%$ respectively, which is in agreement of previous findings [25]. Therefore,

Table 3 Differential diagnostic significance of TNF- $\alpha$, IFN- $\gamma$ and ADA 2

\begin{tabular}{llllll}
\hline Bio-parameter & AUC & Cut-off & Sensitivity (\%) & Specificity (\%) & Accuracy (\%) \\
\hline TNF-a & $0.976^{*}$ & $30.3(\mathrm{ng} / \mathrm{L})$ & 83.0 & 97.0 & 90.0 \\
$\mathrm{IFN}-\boldsymbol{1}$ & $0.831^{\#}$ & $103.65(\mathrm{ng} / \mathrm{L})$ & 80.9 & 81.4 & 81.1 \\
$\mathrm{ADA}{ }_{2}$ & $0.844^{\# \#}$ & $29.45(\mathrm{U} / \mathrm{L})$ & 76.6 & 97.0 & 86.7 \\
$\mathrm{ADA}$ & 0.779 & $39.00(\mathrm{U} / \mathrm{L})$ & 76.6 & 83.7 & 80.0 \\
\hline
\end{tabular}

Compared with $\mathrm{ADA}^{*} X^{2}=0.201, \mathrm{p}>0.05 ;{ }^{\#} X^{2}=0.655, p>0.05 ;{ }^{\# \#} \chi^{2}=0.81, p>0.05$. 
Table 4 Combined-biochemical parameters' diagnostic value analysis

\begin{tabular}{llll}
\hline Bio-parameter & Sensitivity (\%) & Specificity (\%) & Accuracy (\%) \\
\hline TNF- $a+$ IFN- $\gamma$ & 81.9 & 89.5 & 85.6 \\
TNF- $a+$ ADA $_{2}$ & 78.9 & 97.7 & 88.3 \\
IFN- - + ADA 2 & 78.7 & 89.5 & 83.9 \\
TNF- $a+$ IFN- $\gamma+$ ADA $_{2}$ & 80.0 & 92.2 & 85.9 \\
\hline
\end{tabular}

we confirmed that TNF- $\alpha$ could be used for discriminating diagnosis of pleural effusions, from TB and malignant outcomes.

Another Th1 subset cytokine, IFN- $\gamma$, secreted by activated lymphocytes enhances the anti-myobacterial properties of macrophages and induces TNF. Both IFN- $\gamma$ and TNF- $\alpha$ present near the local concentrations area in pleural fluid of $\mathrm{TB}$, which are useful for the bacilli elimination and granuloma formation [27]. In addition, activated by TNF, macrophages produce large amount of nitric oxide (NO), with which, could eliminate $M$. tuberculosis efficiently [28]. Our study showed a significant increase of IFN- $\gamma(114.97 \pm 27.85 \mathrm{ng} / \mathrm{L})$ in pleural fluid of $\mathrm{TB}$ than that of malignant cases $(87.15 \pm 18.77 \mathrm{ng} / \mathrm{L})$. With a cut off of $103.65(\mathrm{ng} / \mathrm{L})$, it yielded mild sensitivity $(80.9 \%)$ and specificity $(81.4 \%)$, although it is less powerful than TNF- $\alpha$.

However, when compared with IFN- $\gamma$ and TNF- $\alpha$, the potential diagnostic value of IL-10 was poorly investigated. According to Olobo's report [28], pleural IL-10 was accumulated in TB. However, in this study, we found that there was no statistical significance of pleural level of IL-10 in $\mathrm{TB}$ and malignant pleural effusions.

In addition, ROC curve analysis indicates the area under the curve (AUC) of IFN- $\gamma$, TNF- $\alpha$ and $\mathrm{ADA}_{2}$ were $0.831,0.976$ and 0.844 respectively. Therefore we confirmed that all of these three bio parameters are of great reliability for the diagnosis of tuberculous pleural effusion. With the greatest AUC (0.976), the sensitivity, specificity and accuracy of TNF- $\alpha$ are $83 \%, 97 \%$ and $90 \%$ respectively. $\mathrm{ADA}_{2}$ yielded comparable diagnostical values, AUC was 0.844 , sensitivity was $76.6 \%$, specificity was $97 \%$, and accuracy was $86.7 \%$. With the sensitivity of $80.9 \%$ and specificity of $81.4 \%$, IFN- $\gamma$ was of less clinical accuracy than TNF- $\alpha$ and $\mathrm{ADA}_{2}$. However, IL-10 was found not to be useful for the diagnosis.

Based on the fact above, IFN- $\gamma$, TNF- $\alpha$, ADA and $\mathrm{ADA}_{2}$ would be the preferred choice to be used to discriminate if the patient is TPE or MPE. But in the clinical practices, to avoid any misdiagnose of diseases, the discriminating diagnosis is determined by taking many factors into account, rather than by testing any single method [18]. The combinations of two or more biomarkers are required to be positive for a diagnosis to be made, which increased the specificity at the expense of sensitivity. Although TNF- $\alpha$ or ADA2 were shown to be effective when used individually for differential diagnosing of TPE from MPE, the combinations of these two biomarkers should result in an improved sensitivity or specificity in reality. Our findings supported that the combination of TNF- $\alpha$ and $\mathrm{ADA}_{2}$ result in the optimal sensitivity of $78.9 \%$, specificity of $97.7 \%$ and accuracy of $88.3 \%$. Therefore, the combinations of TNF- $\alpha$ and ADA2 could effectively address the challenge of distinguishing tuberculous pleural effusion from malignant pleural effusion.

\section{Conclusion}

In conclusion, our investigation suggested that, compared to malignant pleural effusion, IFN- $\gamma$, TNF- $\alpha$, ADA and $\mathrm{ADA}_{2}$ all increased in tuberculous pleural effusion. In addition, combinations of TNF- $\alpha$ and ADA2 yielded the optimal clinical accuracy on making differential diagnose between TPE and MPE.

The number of patients in this study would not be sufficient to deduce a conclusion for a diagnostic accuracy study. A future research with a larger sample analysis will be done to confirm the conclusion drawn in this study.

\section{Abbreviations}

TPE: Tuberculous pleural effusion; MPE: Malignant pleural effusion; TNF-a: Tumor necrosis factor-alpha; IFN- $\gamma$ : Interferon-gamma; IL-10: Interlukine-10; ADA $_{2}$ : Adenosine deaminase 2; ADA: Adenosine deaminase; IAP: Immunosuppressive acidic protein; ROC curve: Receiver operating characteristic curve.

\section{Competing interests}

The authors declare that they have no competing interests.

\section{Authors' contributions}

$M L$ was responsible for all data of the study and modified the manuscript. HW, XX, XW, JW and JW performed the trial and collected all data. HW and $X X$ wrote the draft. All authors read and approved the final manuscript.

Received: 14 November 2013 Accepted: 5 May 2014

Published: 1 July 2014

\section{Reference}

1. Marel M, Zrustova M, Stasny B, Light RW: The incidence of pleural effusion in a well-defined region. Epidemiologic study in central Bohemia. Chest 1993, 104(5):1486-1489.

2. Gopi A, Madhavan SM, Sharma SK, Sahn SA: Diagnosis and treatment of tuberculous pleural effusion in 2006. Chest 2007, 131(3):880-889.

3. Khalsa AM: Preventive counseling, screening, and therapy for the patient with newly diagnosed HIV infection. Am Fam Physician 2006, 73(2):271-280.

4. Valdes L, Pose A, San Jose E, Martinez Vazquez JM: Tuberculous pleural effusions. Eur J Intern Med 2003, 14(2):77-88.

5. Liam CK, Lim KH, Wong CM: Causes of pleural exudates in a region with a high incidence of tuberculosis. Respirology 2000, 5(1):33-38.

6. Ferrer J: Pleural tuberculosis. Eur Respir J 1997, 10(4):942-947.

7. Ciledag A, Kaya A, Erol S, Sen E, Celik G, Cesur S, Fidan Y, Kinikli S: The comparison of pleural fluid TNF-alpha and IL-10 levels with ADA in tuberculous pleural effusion. Curr Med Chem 2010, 17(19):2096-2100.

8. Epstein DM, Kline LR, Albelda SM, Miller WT: Tuberculous pleural effusions. Chest 1987, 91(1):106-109.

9. Escudero Bueno C, Garcia Clemente M, Cuesta Castro B, Molinos Martin L, Rodriguez Ramos S, Gonzalez Panizo A, Martinez Glez-Rio J: Cytologic and bacteriologic analysis of fluid and pleural biopsy specimens with Cope's needle. Study of 414 patients. Arch Intern Med 1990, 150(6):1190-1194. 
10. Scharer $\mathrm{L}, \mathrm{McClement} \mathrm{JH}$ : Isolation of tubercle bacilli from needle biopsy specimens of parietal pleura. Am Rev Respir Dis 1968, 97(3):466-468.

11. Gao ZC, Tian RX: Clinical investigation on diagnostic value of interferon-gamma, interleukin-12 and adenosine deaminase isoenzyme for tuberculous pleurisy. Chin Med J (Engl) 2005, 118(3):234-237.

12. Valdes L, San Jose E, Ferreiro L, Golpe A, Gude F, Alvarez-Dobano JM, Pereyra MF, Toubes ME, Gonzalez-Barcala FJ: Interleukin 27 could be useful in the diagnosis of tuberculous pleural effusions. Respir Care 2014, 59(3):399-405.

13. Hua CC, Chang LC, Chen YC, Chang SC: Proinflammatory cytokines and fibrinolytic enzymes in tuberculous and malignant pleural effusions. Chest 1999, 116(5):1292-1296.

14. Dinarello CA: Anti-cytokine therapeutics and infections. Vaccine 2003, 21(Suppl 2):S24-S34.

15. Law K, Weiden M, Harkin T, Tchou-Wong K, Chi C, Rom WN: Increased release of interleukin-1 beta, interleukin-6, and tumor necrosis factoralpha by bronchoalveolar cells lavaged from involved sites in pulmonary tuberculosis. Am J Respir Crit Care Med 1996, 153(2):799-804.

16. Lyons MJ, Yoshimura T, MCMurray DN: Mycobacterium bovis BCG vaccination augments interleukin-8 mRNA expression and protein production in guinea pig alveolar macrophages infected with Mycobacterium tuberculosis. Infect Immun 2002, 70(10):5471-5478.

17. Soderblom T, Nyberg P, Teppo AM, Klockars M, Riska H, Pettersson T: Pleural fluid interferon-gamma and tumour necrosis factor-alpha in tuberculous and rheumatoid pleurisy. Eur Respir J 1996, 9(8):1652-1655.

18. Wu YB, Ye ZJ, Qin SM, Wu C, Chen YQ, Shi HZ: Combined detections of interleukin 27, interferon-gamma, and adenosine deaminase in pleural effusion for diagnosis of tuberculous pleurisy. Chin Med J (Engl) 2013, 126(17):3215-3221.

19. Muraoka T, Katsuramaki T, Shiraishi H, Yokoyama MM: Automated enzymatic measurement of adenosine deaminase isoenzyme activities in serum. Anal Biochem 1990, 187(2):268-272.

20. Burgess $\sqcup$, Maritz FJ, Le Roux I, Taljaard JJ: Combined use of pleural adenosine deaminase with lymphocyte/neutrophil ratio. Increased specificity for the diagnosis of tuberculous pleuritis. Chest 1996 109(2):414-419.

21. Liang QL, Shi HZ, Wang K, Qin SM, Qin XJ: Diagnostic accuracy of adenosine deaminase in tuberculous pleurisy: a meta-analysis. Respir Med 2008, 102(5):744-754.

22. Villegas MV, Labrada LA, Saravia NG: Evaluation of polymerase chain reaction, adenosine deaminase, and interferon-gamma in pleural fluid for the differential diagnosis of pleural tuberculosis. Chest 2000 118(5):1355-1364

23. Yamada Y, Nakamura A, Hosoda M, Kato T, Asano T, Tonegawa K, Itoh M: Cytokines in pleural liquid for diagnosis of tuberculous pleurisy. Respir Med 2001, 95(7):577-581.

24. Pal Mrinal DS: Adenosine deaminase and its isoenzyme as a diagnostic marker in tubercular plural effusion. J Drug Deliv Ther 2014, 4(1):18-21.

25. Tahhan M, Ugurman F, Gozu A, Akkalyoncu B, Samurkasoglu B: Tumour necrosis factor-alpha in comparison to adenosine deaminase in tuberculous pleuritis. Respiration 2003, 70(3):270-274.

26. Maeda J, Ueki N, Ohkawa T, Iwahashi N, Nakano T, Hada T, Higashino K: Local production and localization of transforming growth factor-beta in tuberculous pleurisy. Clin Exp Immunol 1993, 92(1):32-38.

27. Cooper AM, Adams LB, Dalton DK, Appelberg R, Ehlers S: IFN-gamma and NO in mycobacterial disease: new jobs for old hands. Trends Microbiol 2002, 10(5):221-226.

28. Olobo JO, Geletu M, Demissie A, Eguale T, Hiwot K, Aderaye G, Britton S: Circulating TNF-alpha, TGF-beta, and IL-10 in tuberculosis patients and healthy contacts. Scand J Immunol 2001, 53(1):85-91.

doi:10.1186/1749-8090-9-118

Cite this article as: Li et al:: Diagnostic accuracy of tumor necrosis factor-alpha, interferon-gamma, interlukine-10 and adenosine deaminase 2 in differential diagnosis between tuberculous pleural effusion and malignant pleural effusion. Journal of Cardiothoracic Surgery 2014 9:118

\section{Submit your next manuscript to BioMed Central and take full advantage of:}

- Convenient online submission

- Thorough peer review

- No space constraints or color figure charges

- Immediate publication on acceptance

- Inclusion in PubMed, CAS, Scopus and Google Scholar

- Research which is freely available for redistribution

Submit your manuscript at www.biomedcentral.com/submit
Biomed Central 